pain haematuria syndrome actually exists. How could anyone who believes thus have diagnosed anything other than the loin pain haematuria syndrome in the patients whom we described? We are not ready to rename their condition Hutchison's syndrome. Furthermore, we do not think that our patients had miscellaneous functional disorders, although we understand that neither does Dr Hutchison, and we agree with the important point he makes in noting that some of these patients may have frank neurotic features.

Phase contrast microscopy is certainly valuable in differentiating between glomerular and nonglomerular haematuria, and Dr Hutchison's observation of glomerular origin in the loin pain haematuria syndrome is as expected. His criticism at this point is quite justified.

His comment on $\mathrm{C} 3$ deposition is mere repetition of what we observed and what has been reported from North Staffordshire Hospital Centre, Stoke on Trent.' In this syndrome C3 deposition is observed in the cortical arteries and arterioles. In addition, in 7 out of 14 cases small amounts were reported in a fine granular pattern on the glomerular basement membrane. ${ }^{2}$

The other main criticism that Dr Hutchison makes concerns our suggestion that intrarenal arterial spasms may have a role in the loin pain haematuria syndrome. We do not deny the existence of focal or generalised vascular lesions such as microaneurysms in more advanced cases, as Dr Hutchison calls them, or in a subgroup of patients. We suggest that the mechanism for loin pain in this syndrome might be renal cortical ischaemia, caused in some patients by arterial spasm mediated by the autonomic nervous system. In other patients the same mechanism might be caused by structural changes, such as aggressive atherosis leading to microembolic lesions and the formation of microaneurysms. The effects of arterial spasms would obviously depend on the extent and duration of the spasm. Earlier observations of the reduction of pain after splanchnic nerve blockade, renal denervation, and autotransplantation of the affected kidney to a heterotopic location in the iliac fossa support our hypothesis. ${ }^{34}$

Arterial spasms are rare during renal angiography; in a series of more than $\mathbf{4 0 0}$ renal angiograms using the Seldinger technique selective angiograms in two patients showed three forms of defects attributed to renal arterial spasms. ${ }^{5}$ We do not believe that it would be possible, however, using the description of an angiographic technique, to derive the frequency of intrarenal arterial spasms provoked by that procedure. We still think that it is more useful to compare the frequency of spasms in patients with the loin pain haematuria syndrome with the frequency observed in patients with other conditions, studied using exactly the same angiographic technique, as we did in our report. Three of the patients had spasms and five did not, and one control had a spasm while 32 did not; Pearson's $\chi^{2}$ test with Yates's correction would thus give a $p$ value $<0 \cdot 05$. Even so, we agree that still more detailed description of intrarenal arterial spasm would be welcome.

YRJO T KONTTINEN DAN NORDSTROM VILLE BERGROTH

Helsinki University Central Hospital, SF-00170 Helsinki, Finland

1 Fletcher P, Al-Khader AA, Parsons V, Aber GM. The pathology of intrarenal vascular lesions associated with the loin-painhaematuria syndrome. Nephron 1979;24:150-4.

2 Naish PF, Aber GM, Boyd WN. C3 deposition in renal arterioles in the loin pain and haematuria syndrome. $\mathrm{Br}$ Med $\mathrm{J}$ 1975;iii: in the.

3 Aber GM, Higgins PM. The natural history and management of the loin pain/haemataria syndrome. BrF.Urol 1982;54:613-5.
4 Sheil AGR, Ibels LS, Thomas MAB, Graham JC. Renal autotransplantation for severe loin-pain/haematuria syndrome. Lanicet 1985;ii:1216-7.

5 Spriggs DW, Brantley RE. Recognition of renal artery spasm dưing renal angiography, Radiology 1978;127:363-6:

\section{AIDS: a faltering step}

SIR,-As a research group working on the acquired immune deficiency syndrome (AIDS) in Nigeria, we have followed with considerable interest the various political undertones that have tended to characterise opinion among professional associations, and the Euro-American society generally, regarding the unfortunate outbreak of this disease. While acknowledging the moderate posture of the British people generally abou AIDS, we were particularly puzzled by the resolution that allows British doctors to test patients for infection with the human immunodeficiency viru (HIV) without consent (11 July, p 150). One important but clearly undesirable effect of this decision would be to introduce discrimination into the practice of British medicine, but this is not our main concern. Like Professor Michael Adler and Dr D J Jeffries (11 July, p 73), we believe that this decision is likely to alienate patients from their doctors, the obvious loser in the final analysis being British medicine.

There can be no professional, ethical, or legal justification for subjecting unsuspecting patients to mandatory testing for HIV infection, just as there can be no justification (as rightly pointed ou by Professor Adler and Dr Jeffries) for subjecting them to mandatory treatment of any kind.

We have examined semen samples from over 12000 Nigerian subjects from several different socioeconomic (and risk) groups for HIV, and our experience suggests that this virus is of low infectivity. We reaffirm that the risks to health workers are negligible: repeated testing of laboratory workers who carried out the screening proved negative for HIV antibodies, and the one nurse who accidentally pricked himself with a needle used to inject a patient who subsequently died remained negative a year later.

Those of us with some British training have applauded British medical practices in the belief that they are usually pragmatic, while being fair and, in most cases, right. That view has been sullied by this one decision, which is retrogressive and wrong, and which should be reversed at the earliest possible opportunity.

\section{IDRIS MOHAMMED}

J O CHIKWEM

University of Maiduguri Teaching Hospital, TO HARRY Maiduguri, Nigeria

Federal Vaccine Production Laboratory,

A NASIDI Lagos, Nigeria

\section{After safe sex, safe surgery?}

SIR,-Mr Justin Cobb's article (27 June, p 1667) discussing the risks of contamination with blood in the "surgical fast lane" was both entertaining and timely. In this hospital we have recently attempted to define more clearly the risk of contamination that surgeons take each time they put knife to skin.

The general surgical staff consists of three consultants, one senior registrar, and three prefellowship registrars. Over five weeks each surgeon was asked to examine his hands for blood contamination at the end of each procedure after removing his gloves. If contamination of the fingers with blood was confirmed the surgeon was then asked if he was aware that a glove had been perforated during the operation.
Number of operations performed by members of surgical staff, with number of contamination incidents in parentheses

\begin{tabular}{lccc}
\hline & \multicolumn{3}{c}{ Type of operation } \\
\cline { 2 - 4 } & Major & Intermediate & Minor \\
\hline Consultant & $54(23)$ & $65(6)$ & $11(0)$ \\
Senior registrar & $46(21)$ & $51(3)$ & $19(0)$ \\
Registrar & $51(16)$ & $76(9)$ & $22(0)$ \\
\hline \multicolumn{1}{c}{ Total } & $151(60)$ & $192(18)$ & $52(0)$ \\
\hline
\end{tabular}

The operations were classified as major (including extramajor and complex), intermediate, or minor after consultation with published tables and included all planned and emergency surgery but excluded endoscopic urological procedures. The table shows the respective numbers of operations performed, tógether with contamination incidents.

It is an everyday occurrence for surgeons to find at least one hand stained with the patient's blood at the end of a major procedure. We were, however, surprised to find that the incidence is almost $50 \%$ and is not necessarily related to experience. Furthermore, in only 44 of a total of 78 contamination incidents was the surgeon aware that he had perforated his glove; this was a needlestick injury in every case except one, in which the assistant's scissors were at fault.

Clearly, the bigger the operation the greater the risk of blood contamination for the surgeon. In general surgery, where the "no touch technique" is largely inappropriate, this problem is not only exceedingly common but probably unavoidable as it often goes unnoticed. Unless an impervious yet sensitive surgical glove is developed the solution to the risk of transmissible disease must lie with some form of biological rather than mechanical protection.

K LAFFERTY A P WYATT

Brook General Hospital

London SE18 4LW

\section{Halothane hepatitis in children}

SIR,-I would like to raise several questions about the study by Dr J Gerald Kenna and coworkers ( 9 May, p 1209).

Firstly, Dr Kenna and colleagues report on seven patients referred to them for evaluation of postoperative jaundice and on their diagnostic criteria, which entailed an assay for halothane antibodies. As there is no clinical or pathological test to differentiate hepatitis secondary to halothane from hepatitis secondary to a viral aetiology, they used a test for halothane antibodies. ${ }^{1}$ The antibody test itself has problems as it is not specific. In the original article the markers were absent not only in patients who had received halothane and who had evidence of liver dysfunction postoperatively but also in those who were not jaundiced postoperatively.

Dr Kenna and coworkers state that the children were tested for markers for hepatitis $A$ and hepatitis $B$ virus, but $5 \%$ of children admitted to the hospital for hepatitis will have non- $A$, non-B hepatitis. At present, there is no marker for non- $A$, non-B hepatitis, and thus the exclusion of patients with markers for hepatitis $A$ and hepatitis $B$ virus does not exclude those with non-A, non-B hepatitis.

Dr Kenna and colleagues also state that $\alpha_{1}$ antitrypsin deficiency is considered to be a risk factor for hepatitis after halothane anaesthesia, referring to the paper by Wark. ${ }^{2}$ Wark's paper, however, contains no such statement. Burke et al, on the other hand, mention this increased 
sensitivity to halothane in children with $\alpha_{1}$ antitrypsin deficiency, ${ }^{3}$ but they refer to an article in the New England Fournal of Medicine. ${ }^{4}$ Again, there is no mention of this sensitivity. This is an example of an error compounded through misreading and referencing.

The authors present seven cases of suspected halothane hepatitis. In case 7, however, they found no halothane antibody, but they still classified this child as having halothane hepatitis, explaining that it is possible that the antibody was produced but was undetectable. In the case report they state that a $31 / 2$ year old boy weighed $1800 \mathrm{~g}$. This is an extremely small child.

Though halothane hepatitis may occur in children, it is extremely rare, and Dr Kenna and coworkers cannot give the incidence that might be expected in children. In a review article on halothane hepatitis Stock et al concluded that there is no diagnostic test that is specific for halothane induced liver damage and that therefore the diagnosis can be made only by excluding all othe causes of postoperative liver dysfunction. ${ }^{5}$ Walton states that non-A, non-B hepatitis may be responsible for halothane hepatitis after a single exposure. ${ }^{6}$ Thus we still cannot define specifically the diagnostic criteria for halothane hepatitis. If it exists it remains extremely rare in children and has an incidence less than that of non- $A$, non- $B$ hepatitis in the general population. An extensive clinical study of preoperative liver function in asymptomatic children who received halothane and were then followed up for a long period would be needed to provide clearer conclusions.

Department of Anesthesiology,

Oral Roberts University

Tulsa,

Oklahoma

1 Vergani D, Mieli-Vergani G, Alberti A, et al. Antibodies to the surface of halothane-altered rabbit hepatocytes in patients with severe halothane associated hepatitis. N Engl J Med 1980;303. 66-71.

2 Wark HJ. Postoperative jaundice in children. The influence of halothane. Anaesthesia 1983;38:237-42.

3 Burke JA, Kiesel JL, Blair J. Antitrypsin deficiency and liver disease in children. Am $\mathcal{F}$ Dis Child 1976;130:621-9.

4 Anonymous. Case 41-1972, case records of the Massachusetts General Hospital: weekly clinicopathological exercises. NEngl F Med 1972;287:763-8.

5 Stock JGL, Strunin L. Unexplained hepatitis following halothane. Anesthesiology 1985;63:424-39.

6 Walton B. Halothane hepatitis in children. Anaesthesia 1986;41 : 575-8.

\section{The cost of nursing}

SIR,-Wolverhampton Health Authority has recently been informed that it must implemen the English Nursing Board circular 86/65/ERDB, which recommends 52 weeks of theoretical in struction for nurses during their three year training In order to achieve even an increase from 30 to 35 weeks of such instruction in this health authority the employment of 25 additional nurses at a yearly cost of $£ 241000$ is said to be required.

This demand has been presented to a health authority that is facing a deficit of approximately $£^{1 / 2 m}$ in the current year and will probably face a similar deficit in the financial year 1988-9. The consequence of not implementing these requirements is withdrawal of approval for Royal College of Nursing training. The finance for this could be found only by limiting medical or technical staff development or by cutting patient services. This dictum was presented to the health authority with no opportunity for consultation or debate, and if all professions within the health service acted in this manner the management of the service would soon become impossible.
There is general doubt whether trainee nurses need to spend one year out of three away from the wards during their training. We are worried that the radical changes to the structure of nursing generated from within the profession are being forced on the health service without due regard for their impact on other professional groups or patient services.

K W M ScotT

Wolverhampton Health Authority,

Wolverhampton WV10 0QP

\section{References for junior doctors}

SIR,-Like other consultants, I receive regular requests for references. In the past year the interval between receiving the request for a reference and the interview itself has decreased so much that it is now almost impossible to ensure that even a previously composed and typed reference arrives in time for an interview. Most recently, I received a request for a reference on a Saturday morning for an interview taking place the following Tuesday. The request for the reference had been posted on the previous day, and a prepaid return envelope was enclosed. Unfortunately, however, the prepayment was for second class postage; even the Post Office admits that it cannot guarantee first class delivery within 24 hours. In this particular case the job was formally advertised well in advance, with a delay between the closing date for applications and interview of two weeks, and thus the delay was administrative.

Consultants should be advised that the failure to supply references may not be due to tardiness on the part of the referee, and they should question management closely about such delays. References remain an important part of the assessment of a candidate for a post.

P G P LAWLER

South Cleveland Hospital,

Cleveland TS4 3BW

\section{Secrecy and distinction awards}

SIR,-Apparently, Sir Walter Russell Brain told Sir James Howie that the secrecy surrounding the names of holders of distinction awards met the wishes of most of those without awards, people in Harley Street wishing to conceal their secret, undistinguished status from a gullible public (11 July, p 108). This was not true, of course; quite the contrary. A survey in 1973 showed that $67.4 \%$ of award holders favoured secrecy whereas only $29 \%$ of consultants without awards wanted it to continue (CCHMS annual report, 1973).

Secrecy is a crucial link in the mythology, doublethink, compromise, and prejudice that disfigure the system. Abolition of secrecy is an essential step if distinction awards are ever to be even roughly fair, and we are sorry that the new Royal College of Pathologists was so easily deflected from its purpose. We wish that our own Royal College of Psychiatrists would make some stand as we are fairly certain that a plebiscite within the college would vote, by a massive majority, in favour of publishing who has what each year.

We have just elected a new president, and perhaps this could serve as an open letter to Dr Birley. Glasnost starting in the Royal College of Psychiatrists? We should be proud, and the rest would follow.

S BOURNE

\section{Points}

Telling patients about their medicines

Mr C W KoENIGSBERger (Lincoln's Inn, London WC2A 3SU)writes: Professor CF George recommends that patients should be told more about their medicines (20 June, p 1566). Before the positive steps he mentions are taken, however, the obstacles that prevent a patient from finding out the details for himself must be removed-for example, does Professor George know that the Association of the British Pharmaceutical Industry's Data Sheet Compendium may be sold only to doctors and other health workers? Accordingly, it cannot be found in an ordinary reference library. The basic restriction is contained in clause 22.1 of the Code of Practice for the Pharmaceutical Industry (revised, 6th edition, January 1986), which requires that requests from individual members of the public for information "must always be refused." This absurd provision hould be abandoned immediately.

\section{Evaluation of portable haemoglobinometer in general practice}

Dr Rodpy Quinn (Ransboro, Sligo, Ireland) writes: The statement by Ms Cathy White and Dr Daisy Obeid (27 June, p 1689) that "there are very few indications for estimating a patient's haemoglobin concentration alone" serves only to show how little the average hospital practitioner understands about general practice and the dynamics between the doctor and the patient in the surgery. Their statement is no doubt true in from a purely haematological viewpoint. As any general practitioner knows, however, physical disease constitutes only a proportion of the daily workload, psychosocial elements looming large in many consultations. I would find an "on the spot" haemoglobin estimation helpful in allaying the unease of the many patients who present with symptoms of tiredness, malaise, lack of energy, no interest in life, etc, which almost invariably have a non-physical origin. The knowledge that the haemoglobin concentration is normal helps the doctor in his or her effort to explain the symptoms and also helps to minimise prescribing.

\section{Lymphoedema of the arm}

Dr Helen J Stewart (Scottish Cancer Trials Office, University of Edinburgh Medical School, Edinburgh EH8 9AG) writes: I was surprised that Professor N L Browse (4 July, p 3) did not mention acute onset lymphoedema secondary to minor skin trauma of the hand some years after postmastectomy axillary irradiation. As Professor Browse rightly stated, the combination of limited sampling of axillary lymph nodes and radical radiotherapy is not associated with a high incidence of secondary lymphoedema. None the less, after two to three years a subclinical reduction in the efficiency of the lymphatic drainage from the arm is likely, making avoidance of precipitating factors worth while. In my experience, acute swelling of the hand and arm may occur after, for example, a superficial burn or simple cut without clinical evidence of local infection or lymphangitis and may even present after the minor trauma has almost healed. In these circumstances prompt antibiotic treatment often leads to total and speedy reversal. In addition, prolonged piano playing, knitting, or similar activities that exercise the hand without arm or shoulder movement may be temporary precipitating factors and should be discouraged if the arm tends to swell. I am sure that most radiotherapists would agree with these comments and advise their patients at risk to take other simple precautions, such as wearing gardening gloves and not playing with cats.

Professor J D E KNox (Westgate Health Centre, Dundee DD2 4AD) writes: Professor N L Browse 4 July, $p$ 3) rightly focuses on the common P BRUGGEN (surgical) causes of the fairly uncommon phenomenon of lymphoedema of the arm because these are the more usual causal factors in secondary lymphoedema. I 